10-15-2002

\title{
Rapid Determination of Serum Melatonin by ESI-MS-MS with Direct Sample Injection
}

\author{
Shuming Yang \\ Cleveland State University \\ Xiaohui Zheng \\ Cleveland State University \\ Yan Xu \\ Cleveland State University, y.xu@csuohio.edu \\ Xiang Zhou \\ Cleveland State University
}

Follow this and additional works at: https://engagedscholarship.csuohio.edu/scichem_facpub

Part of the Analytical Chemistry Commons

How does access to this work benefit you? Let us know!

\section{Recommended Citation}

Yang, Shuming; Zheng, Xiaohui; Xu, Yan; and Zhou, Xiang, "Rapid Determination of Serum Melatonin by ESI-MS-MS with Direct Sample Injection" (2002). Chemistry Faculty Publications. 208.

https://engagedscholarship.csuohio.edu/scichem_facpub/208

This Article is brought to you for free and open access by the Chemistry Department at EngagedScholarship@CSU. It has been accepted for inclusion in Chemistry Faculty Publications by an authorized administrator of EngagedScholarship@CSU. For more information, please contact library.es@csuohio.edu. 


\title{
Rapid determination of serum melatonin by ESI-MS-MS with direct sample injection
}

\author{
Shuming Yang Xiaohui Zheng Yan Xu Xiang Zhou
}

\section{Introduction}

Melatonin (Fig. 1) is a hormone secreted from the pineal gland in brain, which plays an important role in the regulation of circadian sleep-wake cycle [1]. The concentration of melatonin in blood is changeable with the circadian rhythm, low around $10 \mathrm{pg} / \mathrm{ml}$ in the daytime and high around $25-120 \mathrm{pg} / \mathrm{ml}$ at night [2]. Melatonin has been orally administered to help patient with jet lag [3], seasonal depression and anxiety symptom [4]. Animal experiment shows that it can improve the immune system and retard the aging process [5]. Melatonin is also a good radical scavenger, suggesting its possible use in the prevention of some forms of cancers [6,7]. Generally, plasma melatonin levels are maintained at about 25-800 times higher than the endogenous peak values after oral administration $(1-10.0 \mathrm{mg})[8,9]$.

Due to its low concentration and the co-existence of many other endogenous compounds in blood, the determination of melatonin has been an analytical challenge [10]. Current analytical 
methods available for blood melatonin include enzyme immunoassay (EIA) [11], radioimmunoassay (RIA) [12], GC-MS methods [13,14], HPLC with fluorescence detection [15,16], and HPLC with electrochemical detection [17], etc. Although EIA and RIA were very sensitive for the determination of melatonin in blood, some anticoagulants and endogenous interfering compounds may affect their specificity $[11,12]$. The other chromatography-based methods [13-15,17] require prior sample preparations (e.g. liquid-liquid extraction or solid-phase extraction) to remove serum proteins and interfering compounds, which are usually time-consuming and laborious. In case of $\mathrm{GC}-\mathrm{MS}$ methods $[13,14]$, derivatization of melatonin is needed prior to the analysis.

The purpose of this work is to develop a rapid, sensitive and specific analytical method for the quantitative determination of serum melatonin by ESI-MS-MS with direct sample injection, which employs an on-line sample extraction procedure.

\section{Experimental}

\section{Chemicals and solutions}

Melatonin ( $N$-acetyl-5-methoxytryptamine) and $\mathrm{N}$-acetyltryptamine (internal standard) were obtained from Sigma (St Louis, MO, USA). Ammonium formate, formic acid, HPLC grade water

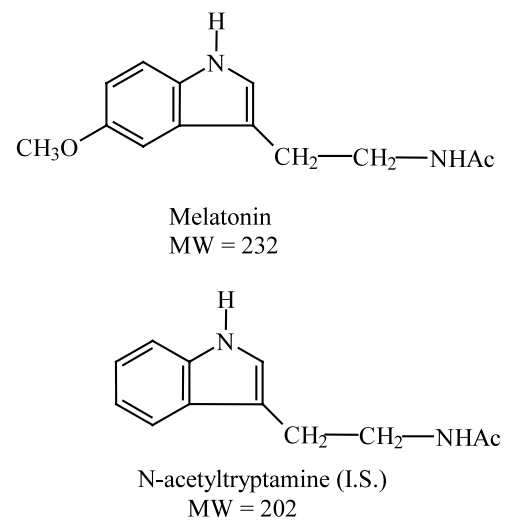

Fig. 1. Molecular structure of melatonin and the internal standard, $N$-acetyltryptamine. and acetonitrile were from Aldrich (Milwaukee, WI, USA). Human sera (cat. number S7023, lot number 120K8972) was purchased from Sigma and kept at $-20{ }^{\circ} \mathrm{C}$.

A stock solution of ammonium formate (50 $\mathrm{mM}, \mathrm{pH} 4.0$ ) was prepared by dissolving appropriate amounts of ammonium formate in a known volume of HPLC grade water. The $\mathrm{pH}$ of the solution was adjusted to the desired value with formic acid. Five $\mathrm{mM}$ ammonium formate at $\mathrm{pH}$ 4.0 was prepared by 1:10 dilution of the stock solution with HPLC grade water.

Stock solutions $(1.00 \mathrm{mg} / \mathrm{ml})$ of melatonin and $N$-acetyltryptamine $(0.500 \mathrm{mg} / \mathrm{ml}$, internal standard) were prepared by dissolving appropriate amounts of each compound in a known volume of methanol, which were stored at $-20{ }^{\circ} \mathrm{C}$ when not used.

Working standard solutions of melatonin (8.00, $80.0, \quad 600$ and $1000 \mathrm{ng} / \mathrm{ml})$ and $N$-acetyltryptamine $(8.00,80.0,200$ and $600 \mathrm{ng} / \mathrm{ml})$ were prepared by serial dilution of the stock solutions with $5 \mathrm{mM}$ ammonium formate $(\mathrm{pH} \mathrm{4.0)}$ ).

\section{Blank sera, serum standards and samples}

Human sera contained no detectable melatonin were used as the blank sera. Serum standards $(0.500,1.00,2.00,5.00,15.0,50.0,100$ and 200 $\mathrm{ng} / \mathrm{ml}$ ) were prepared by the serial dilution of the $1000-\mathrm{ng} / \mathrm{ml}$ melatonin working standard solution with the blank sera.

Prior to the analysis, $10-\mu 1$ internal standard solution ( $N$-acetyltryptamine, $200 \mathrm{ng} / \mathrm{ml}$ in $5 \mathrm{mM}$ ammonium formate at $\mathrm{pH}$ 4.0) was added to $200-\mu 1$ serum standards and serum samples. The mixtures were diluted with $190-\mu \mathrm{l}, 5 \mathrm{mM}$ ammonium formate $(\mathrm{pH} 4.0)$. After vortex mixing, these solutions were transferred to autosampler vials for instrument analysis.

\section{Instrumentation}

The instrumentation system used for this work consisted of an HP1100 pump (Hewlett-Packard, Palo Alto, CA, USA), an HP1100 autosampler, a stainless steel in-line filter $(0.5-\mu \mathrm{m}$ pore, $0.23-\mu 1$ dead volume, Upchurch Scientific, Oak Harbor, 


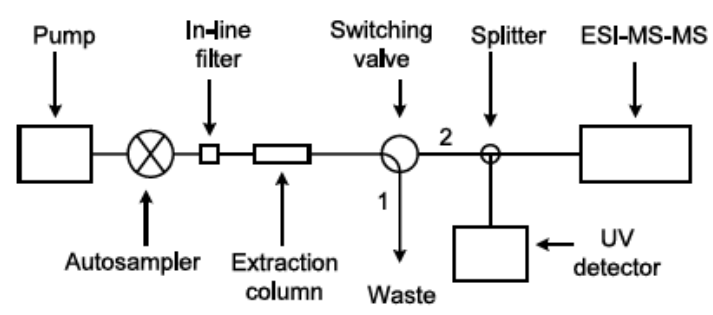

Fig. 2. Block diagram of the instrumentation system.

Table 1

The flow profile of the instrumentation system

\begin{tabular}{lrrl}
\hline Time (min) & A (\%) & B (\%) & Flow rate $(\mathrm{ml} / \mathrm{min})$ \\
\hline 0.0 & 100 & 0 & 1.0 \\
2.0 & 100 & 0 & 1.0 \\
2.1 & 0 & 100 & 0.2 \\
7.5 & 0 & 100 & 0.2 \\
7.6 & 0 & 100 & 1.0 \\
8.0 & 0 & 100 & 1.0 \\
8.1 & 100 & 0 & 1.0 \\
9.0 & 100 & 0 & 1.0 \\
\hline
\end{tabular}

A, $5 \mathrm{mM}$ ammonium formate at $\mathrm{pH} 4.0$. B, $95 \%$ acetonitrile + $5 \% 5 \mathrm{mM}$ ammonium formate at $\mathrm{pH} 4.0$.

WA, USA), an Oasis ${ }^{\circledR}$ HLB extraction cartridge column $(2.1 \times 20 \mathrm{~mm}$, Waters, Milford, MA, USA), a Rheodyne 7000 two-position 6-port switching valve (Supelco, Bellefonte, PA, USA), a stainless steel splitting tee $(1 / 16$ in. $\times 0.25 \mathrm{~mm}$, Valco, Houston, TX, USA), an HP1100 variable wavelength UV detector, and a Quattro II triple quadrupole mass spectrometer (Micromass, Manchester, UK). The fluidic connections of the system is shown in Fig. 2. At the position 1, the extraction buffer from the pump carried the sample from the autosampler to the extraction column where the sample matrix was excluded to the waste and analytes of interest were retained on the column. At the position 2, the elution buffer from the pump eluted the analytes and the internal standard from the extraction column and carried them to the splitter where the flow was diverted to the ESI-MS detector and the UV detector with a split ratio of 1:2. The smaller flow went to the MS detector (ca. $70 \mu \mathrm{l} / \mathrm{min}$ ) and the larger one to the UV detector. For all the connections, high-pressure polyether ether ketone
(PEEK) tubing (0.0625 in. O.D.) was used. From the splitter to the ESI-MS detector, 0.005 in. I.D. tubing was used, and for the rest of connections, 0.01 in. I.D. tubing was used.

\section{On-line sample preparation}

At the position 1 of the switching valve (Fig. 2), Oasis $^{\circledR}$ extraction column was first equilibrated with the extraction buffer $(5 \mathrm{mM}$ ammonium formate at $\mathrm{pH} 4.0$ ) at a flow rate of $1.0 \mathrm{ml} / \mathrm{min}$. Then, a $10-\mu l$ portion of the diluted serum sample was injected by autosampler onto the extraction column. This step excluded the sample matrix to the waste and retained the analytes of interest on the column. After 2-min sample extraction and cleanup, the switching valve was turned to the position 2. At the same time, the extraction buffer was changed to the elution buffer $(95 \%$ acetonitrile $+5 \% 5 \mathrm{mM}$ ammonium formate at $\mathrm{pH} 4.0$ ) with a flow rate of $0.2 \mathrm{ml} / \mathrm{min}$, which initiated the elution of analytes from the extraction column. After 5.5-min elution, the switching valve was turned back to the position 1 . The elution buffer was pumped through the column at $1 \mathrm{ml} / \mathrm{min}$ for $0.5 \mathrm{~min}$ before it was changed back to the extraction buffer. The extraction column was equilibrated with the extraction buffer at $1 \mathrm{ml} / \mathrm{min}$ for $1.0 \mathrm{~min}$ before the next injection. The complete flow profile was summarized in Table 1 and the total run time per sample was $9 \mathrm{~min}$.

\section{ESI-MS-MS detection}

The Quattro II triple quadrupole mass spectrometer was operated in the positive electrospray ionization mode $(\mathrm{ESI}+)$. It was tuned by infusion of a mixture of melatonin and $\mathrm{N}$-acetyltryptamine $(1.00 \mu \mathrm{g} / \mathrm{ml}$ each) in $50 \%$ acetonitrile $+50 \% 5 \mathrm{mM}$ ammonium formate $(\mathrm{pH} 4.0)$ at a flow rate of 3 $\mu \mathrm{l} / \mathrm{min}$ with a syringe pump (Harvard Apparatus, South Natick, MA, USA). The optimzed ionization conditions were: nitrogen sheath and desolvation gas at 10 and $350 \mathrm{l} / \mathrm{h}$, capillary at $3.5 \mathrm{kV}$, HV lens at $0.5 \mathrm{kV}$, cone at $25 \mathrm{~V}$, skimmer at $1.5 \mathrm{~V}$, $\mathrm{RF}$ lens at $0.2 \mathrm{~V}$, ion source temperature at $70{ }^{\circ} \mathrm{C}$, ion energy at $0.6 \mathrm{~V}$, low- and high-mass resolution at 15 , and multiplier at $650 \mathrm{~V}$. 
Full scan spectra were acquired in the continuum mode over the mass range of $180-280 \mathrm{u}$ at the scan rate of $500 \mathrm{u} / \mathrm{s}$. Selected ion recording (SIR) data were acquired by sequentially monitoring quasi-molecular ions of the analytes ([melatonin $+\mathrm{H}]^{+}$at $m / z \quad 233$ and $[N$-acetyltryptamine $+\mathrm{H}]^{+}$at $m / z$ 203) with a span of $0.05 \mathrm{u}$, a dwell time of $0.5 \mathrm{~s}$, and an inter-scan delay of 0.03 $\mathrm{s}$. Ionization parameters were the same as those described above.

Multiple reaction monitoring (MRM) data were acquired with the following parameters: $\mathrm{m} / \mathrm{z}$ $233>174$ for melatonin, $m / z 203>144$ for $N$ acetyltryptamine, argon collision gas at $1.0 \mu \mathrm{bar}$, cone at $25 \mathrm{~V}$, collision energy at $15 \mathrm{eV}$ for each analyte, low- and high-mass resolution at 15 for both quadrupole 1 and 3, dwell time of $0.5 \mathrm{~s}$, and inter-scan delay of $0.03 \mathrm{~s}$. The ionization parameters used for MRM were the same as those for SIR.

\section{Quantitation}

Data acqusition was done by MICROMASS MASSLYNX software (Version 3.4). The peak area ratios of melatonin to the internal standard ( $Y$ axis values) were plotted against the melatonin concentrations ( $X$-axis values) for the regression equation. The serum melatonin concentration of the unknown sample was determined by the regression equation after obtaining the peak area ratio of the unknown to the internal standard from the mass chromatograms.

\section{Recovery}

The three-concentration-level $(2.00,20.0$ and $150 \mathrm{ng} / \mathrm{ml}$ ) serum samples used in the recovery studies were prepared by adding $50-\mu 1$ internal standard ( $N$-acetyltryptamine, at $8.00,80.0$ and $600 \mathrm{ng} / \mathrm{ml}$ in $5 \mathrm{mM}$ ammonium formate at $\mathrm{pH}$ 4.0), 50- $\mu$ melatonin (at 8.00, 80.0 and $600 \mathrm{ng} / \mathrm{ml}$ in $5 \mathrm{mM}$ ammonium formate at $\mathrm{pH} 4.0$ ), and $100-\mu 1$ of $5 \mathrm{mM}$ ammonium formate $(\mathrm{pH} 4.0)$ to $200-\mu \mathrm{l}$ blank serum. The control samples were prepared in $5 \mathrm{mM}$ ammonium formate $(\mathrm{pH} 4.0)$ at the same concentration levels. The recoveries of melatonin and $N$-acetyltryptamine in human sera were determined by comparing the mean peak areas of serum samples to the mean peak areas of the control samples.

\section{Results and discussions}

\section{On-line sample preparation}

Sample preparation is the bottleneck of most of drug analyses in biological fluids. Direct sample injection with on-line sample preparation has been developed to simplify and expedite the analytical procedure for drug analyses. In this work, Waters Oasis ${ }^{\circledR}$ HLB extraction cartridge was used as an on-line column for the extraction of serum melatonin and $N$-acetyltryptamine (internal standard). According to the manufacturer, the packing material of the extraction column is a macroporous copolymer [poly(divinylbenzene-co$N$-vinylpyrrolidone)] and HLB is an acronym for hydrophillic lipophillic balance which describes the dual retention capability of the packing material to retain polar and nonpolar compounds. The water wettable polymeric sorbent of Oasis ${ }^{\circledR}$ HLB allows the exclusion of proteins and other interfering matrix constituents, and the retention of acids, bases and neutral compounds with high and reproducible recoveries [18].

By the experiments shown in Fig. 3, it was found that serum proteins and other interfering matrix constituents were completely eluted in less than 1 min after sample injection using $5 \mathrm{mM}$ ammonium formate $(\mathrm{pH} \mathrm{4.0)}$ at the flow rate of $1.0 \mathrm{ml} / \mathrm{min}$ as the extraction buffer (Fig. 3A). Meanwhile, melatonin, $N$-acetyltryptamine and other endogenous compounds were retained on the column even after 9-min washing with the extraction buffer (Fig. 3B). Therefore, 2-min after sample injection was chosen as the switching time when the switching valve was turned from the position 1 to 2 (Fig. 2). The elution of melatonin and $\mathrm{N}$-acetyltryptamine as well as other endogenous compounds took place after the extraction buffer was changed to the elution buffer $(95 \%$ $\mathrm{CH}_{3} \mathrm{CN}+5 \% 5 \mathrm{mM}$ ammonium formate at $\mathrm{pH}$ $4.0)$ at 2 min of the sample injection. Fig. 3C and $\mathrm{D}$ showed that these compounds reached the UV 
detector after $5.8 \mathrm{~min}$ of sample injection. To avoid the contamination of ESI-MS-MS detector, only UV detector was used to monitor the elution profiles of serum samples in these experiments.

It was also known from the experiments that low percentage of $\mathrm{CH}_{3} \mathrm{CN}$ in the elution buffer would increase the retention time of the analytes and longer retention could result in further dilution of the analytes on the extraction column. In this work, $95 \% \mathrm{CH}_{3} \mathrm{CN}$ was used for the rapid elution of the analytes, and $5 \% 5 \mathrm{mM}$ ammonium formate ( $\mathrm{pH} 4.0$ ) was used to suppress the formation of sodium adducts and to increase the ionization efficiency of the analytes.
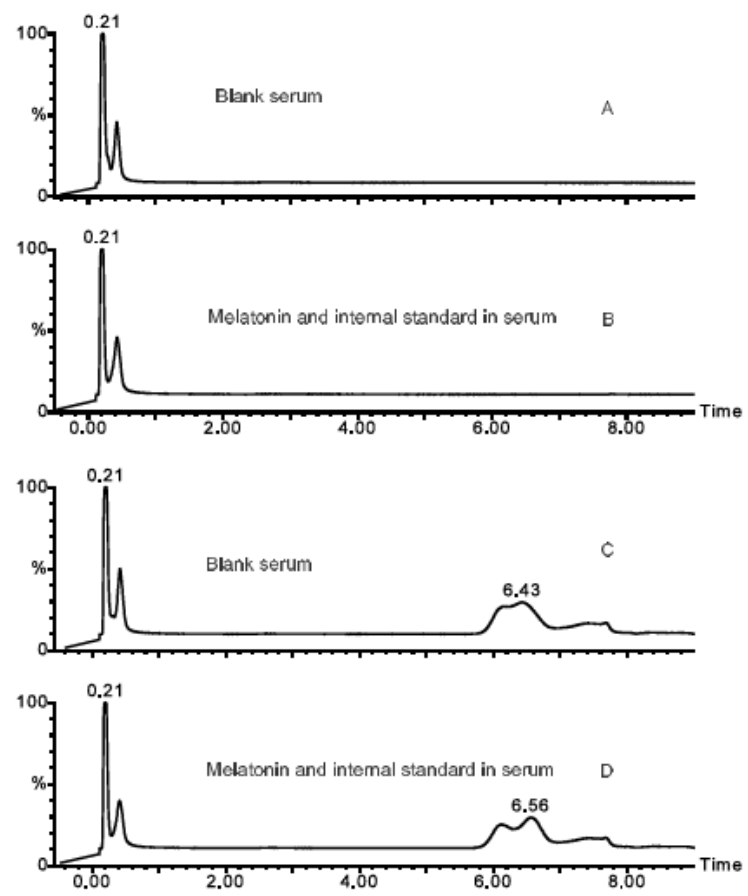

Fig. 3. UV chromatograms of blank human serum (A, C) and human serum spiked with $200 \mathrm{ng} / \mathrm{ml}$ melatonin and $N$-acetyltryptamine (B, D). For A and B, $5 \mathrm{mM}$ ammonium formate at $\mathrm{pH} 4.0$ was the carrier fluid; for $\mathrm{C}$ and $\mathrm{D}$ the carrier fluids was the same as those in Table 1. Instrumentation, Fig. 2 at the position 2 without ESI-MS-MS detector; and UV detection wavelength, $254 \mathrm{~nm}$.
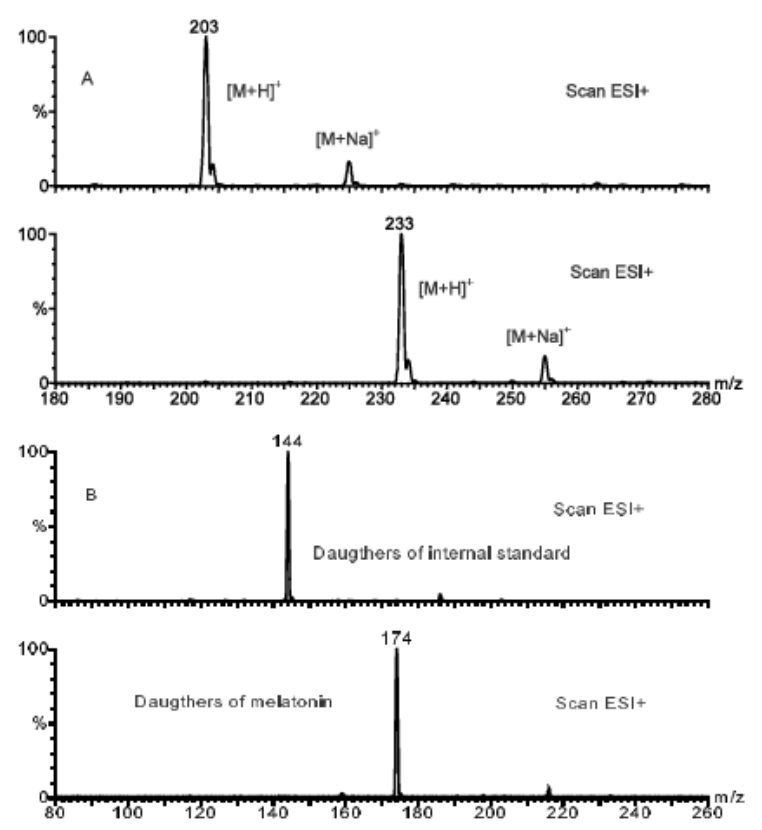

Fig. 4. Positive-ion scan spectra of melatonin and $\mathrm{N}$-acetyltryptamine (internal standard). (A) the parent ions; (B) the daughter ions. Instrumentation system: Fig. 2 without the UV detector. Detection conditions: the same as those described in Section 2.5.

\section{ESI-MS-MS detection}

Melatonin and $\mathrm{N}$-acetyltryptamine are more readily obtaining a proton than losing one in the acidic electrospray ionization conditions; therefore, the positive electrospray ionization mode has been the choice of detection. Full scan spectra over the mass range of $180-280 \mathrm{u}$ revealed that melatonin produced a quasi-molecular ion $[\mathbf{M}+$ $\mathrm{H}]^{+}$at $\mathrm{m} / z 233$ and $\mathrm{N}$-acetyltryptamine at $\mathrm{m} / \mathrm{z}$ 203 (Fig. 4A). By selecting these quasi-molecular ions as parent ions, daughter spectra could be obtained. The prominent daughter ions over the range of $80-260 \mathrm{u}$ were $m / z 174$ for melatonin and $m / z \quad 144$ for $N$-acetyltryptamine (Fig. 4B), which were produced by colliding with argon gas in the quadrupole 2 of the mass spectrometer and losing a neutral fragment of $59 \mathrm{u}\left(\mathrm{CH}_{3} \mathrm{CONH}_{2}\right)$ from the parent ions.

In this work, since no separation column was used, many endogenous interfering compounds co-eluted with melatonin and the internal stan- 
dard from the extraction column. By comparing mass chromatograms of 'single ion recording,
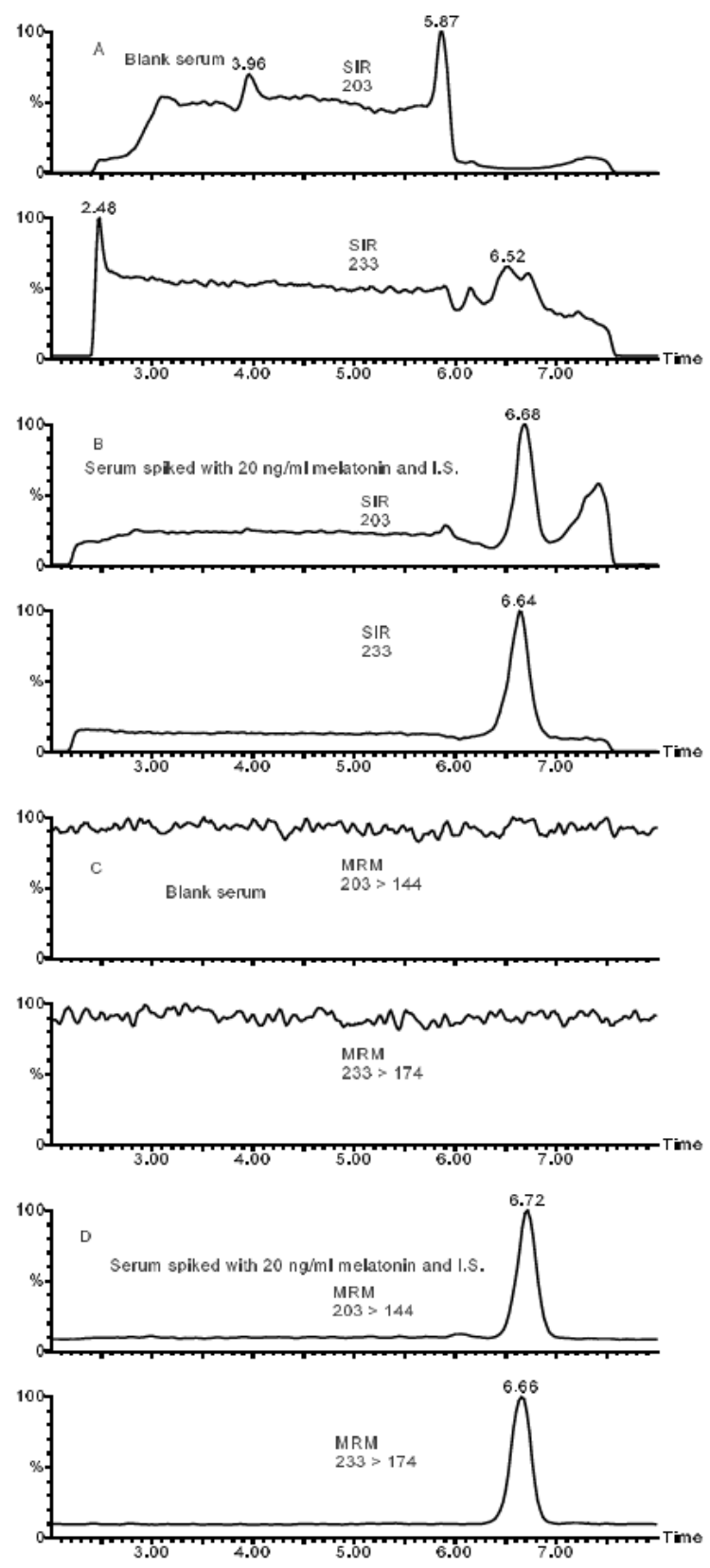

Fig. 5. SIR and MRM chromatograms of melatonin and $\mathrm{N}$-acetyltryptamine in human sera. SIR mode: $\mathrm{m} / z 233$ for melatonin and $m / z 203$ for $N$-acetyltryptamine. MRM mode: $m / z 233>174$ for melatonin and $m / z 203>144$ for $N$-acetyltrypamine. Experiment conditions, the same as those in Fig. 4.
SIR' (Fig. 5A and B) to those of MRM (Fig. 5C and D), it was clearly evident that MRM mode experienced no interference from the sample matrix. Therefore, it was chosen as the detection mode for melatonin quantitation.

The settings of low- and high-mass resolution for quadrupole 1 and 3 could affect both the flux of ions and the noise levels. To obtain the highest signal-to-noise ratio, a setting of 15 for both lowand high-mass resolution was found to be the optimum for this work.

Although a relatively long scan time (dwell time) could decrease the sensitivity a little, it remarkably improved the signal-to-noise ratio. A 0.5 -s scan time was used for the detection of melatonin and the internal standard.

It was also noticed that a low collision gas pressure in the quadrupole 2 could decrease the noise levels in the MRM mode. Therefore, an argon gas pressure of $1.0 \mu \mathrm{bar}$ was chosen for this work.

\section{Flow rate}

The flow rate of the elution buffer affected the detection sensitivity of the MS in rather a remarkable way. It was found that the sensitivity increased as flow rate decreased. As shown in Fig. 6 , the peak areas and heights of melatonin and $N$-acetyltryptamine became larger as the flow rate decreased from 1 to $0.15 \mathrm{ml} / \mathrm{min}$. A reasonable explanation is that ESI-MS is a concentrationsensitive detector. When the amounts of analytes were fixed, the fluidic volumes delivered per unit time were higher at higher flow rates, and the actual concentrations of the analytes in the MS were lower than those at lower flow rates.

It was also noticed that when the flow rate got too small, the elution time and the peak width could become longer and broader. Therefore, a flow rate of $0.2 \mathrm{ml} / \mathrm{min}$ was chosen for the subsequent studies, which gave an adequate detection sensitivity and elution time. At this flow rate, the actual fluid flowed into the MS was about 70 $\mu \mathrm{l} / \mathrm{min}$ due to the post-column splitting at a ratio of $1: 2$. 

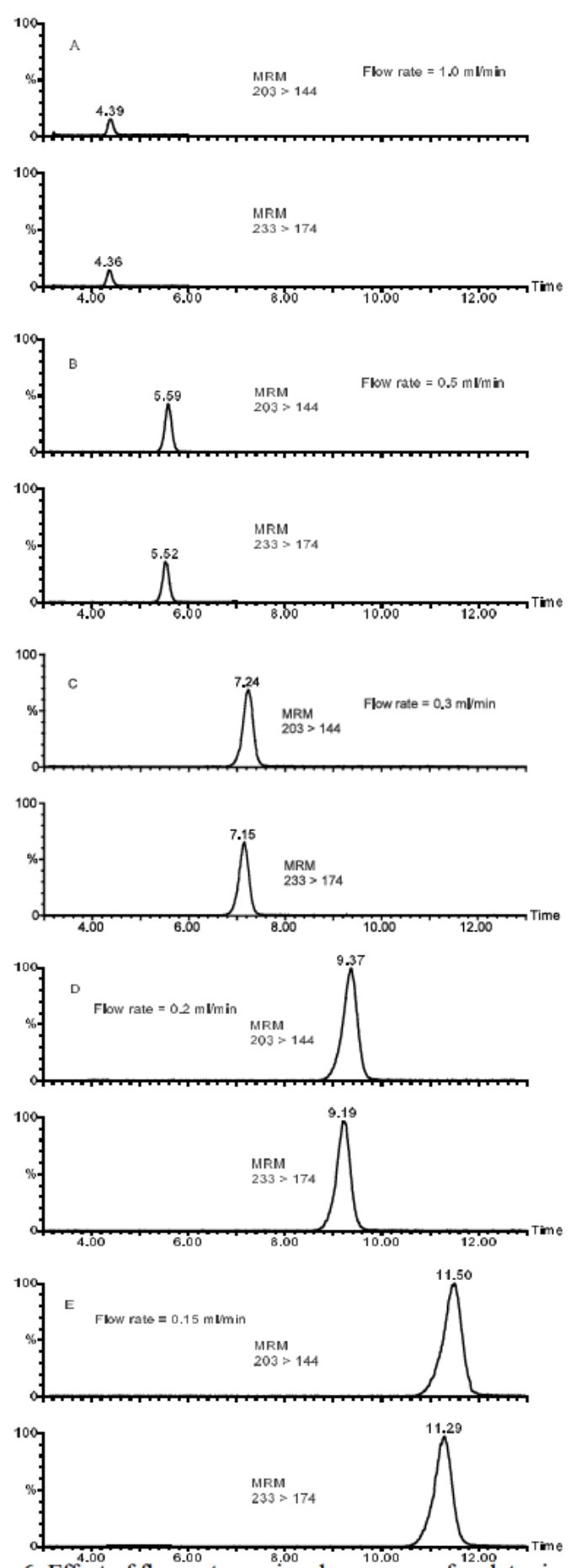

Fig. 6. Effect of flow rate on signal responses of melatonin and $\mathrm{N}$-acetyltrypamine. Experimental conditions were the same as those described in Section 2.4 except the elution buffer were $47.5 \%$ acetonitrile $+52.5 \% 5 \mathrm{mM}$ ammonium formate $(\mathrm{pH}$ 4.0) and the switching time were 3-min after sample injection.
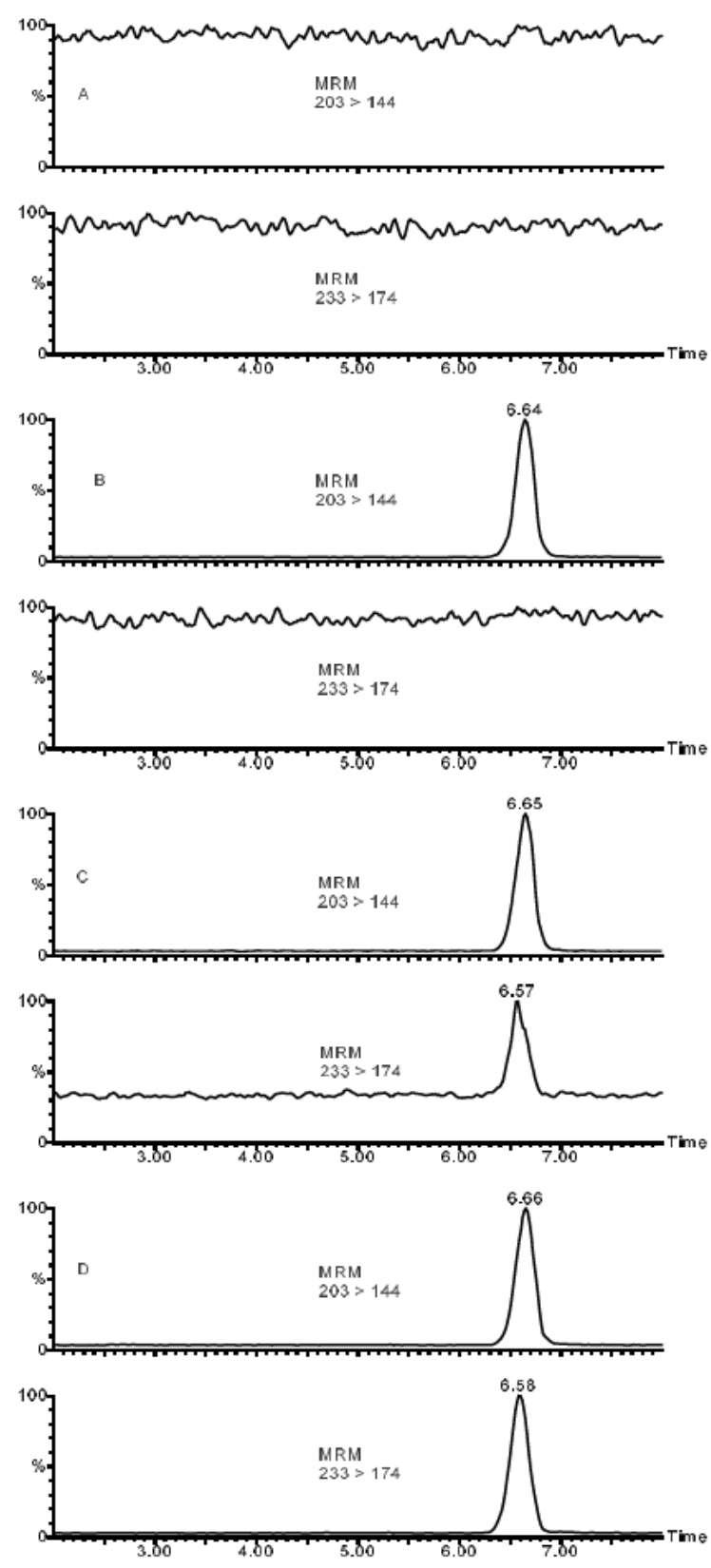

Fig. 7. Mass chromatograms of MRM detection mode. (A) Blank human serum; (B) blank human serum spiked with 20 $\mathrm{ng} / \mathrm{ml} \mathrm{N}$-acetyltrypamine (internal standard); (C) blank human serum spiked with $20 \mathrm{ng} / \mathrm{ml}$ internal standard and $1 \mathrm{ng} / \mathrm{ml}$ melatonin; and (D) blank human serum spiked with $20 \mathrm{ng} / \mathrm{ml}$ internal standard and $20 \mathrm{ng} / \mathrm{ml}$ melatonin. Experiment conditions: the same as those in Fig. 4. Melatonin, $m / z$ 233 > 174; internal standard, $m / z 203>144$. 
Table 2

Recoveries of melatonin and $N$-acetyltryptamine (I.S.) from human sera

\begin{tabular}{|c|c|c|c|c|c|c|}
\hline \multirow[t]{2}{*}{ Compounds ${ }^{\mathrm{a}}$} & \multicolumn{2}{|l|}{$2.00 \mathrm{ng} / \mathrm{ml}$} & \multicolumn{2}{|l|}{$20.0 \mathrm{ng} / \mathrm{ml}$} & \multicolumn{2}{|l|}{$150 \mathrm{ng} / \mathrm{ml}$} \\
\hline & Recovery (\%) & CV $(\%)$ & Recovery (\%) & CV (\%) & Recovery (\%) & CV (\%) \\
\hline Melatonin & 69.1 & 5.1 & 68.9 & 3.6 & 70.5 & 1.9 \\
\hline I.S. & 59.1 & 1.7 & 53.2 & 4.5 & 57.7 & 0.67 \\
\hline
\end{tabular}

Recovery $=$ Mean peak area of serum samples $(n=3)$ /Mean peak area of control samples $(n=3) \times 100 \%$.

${ }^{\text {a }}$ Injection volume $=10 \mu \mathrm{l}$.

\section{Sodium adducts}

Melatonin and $N$-acetyltryptamine could easily form adducts with sodium ion in the positive electrospray ionization process. The formation of sodium adducts $[\mathrm{M}+\mathrm{Na}]^{+}$competed with the formation of quasi-molecular ions $[\mathrm{M}+\mathrm{H}]^{+}$and affected the detection sensitivity. Hence, it should be suppressed. The experiments indicated that ammonium formate was more effective in suppressing the formation of sodium adducts than formic acid; whereas formic acid might cause a low ionization efficiency of the analytes as trifluoroacetic acid (TFA) did in the previous study [19]. For the subsequent studies, 5\% $5 \mathrm{mM}$ ammonium formate ( $\mathrm{pH}$ 4.0) was used with $95 \%$ $\mathrm{CH}_{3} \mathrm{CN}$ as the elution buffer for achieving high detection sensitivity.

\section{Analytical performance}

The MRM mode was used for quantitation. Its specificity for detecting melatonin and $N$-acetyltryptamine was illustrated by the representative mass chromatograms in Fig. 7, which showed no sign of interference from the co-eluting endogenous compounds in the serum matrix.

The recovery studies of melatonin and $N$ acetyltryptamine were conducted at three-concentration levels $(2.00,20.0$ and $150 \mathrm{ng} / \mathrm{ml})$ and the results were summarized in Table 2 . The absolute recoveries of melatonin and $N$-acetyltryptamine were $68.9-70.5$ and $53.2-59.1 \%$, respectively. The recovery data showed good consistency at all levels. It is noted that recoveries of analytes decreased gradually with a sample injection volume greater than $50 \mu$ l (data not shown), which were probably due to the loading capacity of the extraction column at given concentration levels. In this work, an injection volume of $10 \mu \mathrm{l}$ was used for quantitation.

The method developed has excellent intra- and inter-assay precision for melatonin. As shown in Table 3, The relative standard deviations of melatonin at four-concentrations for the within-day (intra-assay) study ranged $0.8-2.0 \%(n=5)$ and the day-to-day (inter-assay) study ranged 1.5$5.9 \%(n=3)$.

A good linear relationship was found between the peak-area ratios of melatonin to $N$-acetyltryptamine (the internal standard) versus the concentrations of melatonin ranging 0.500-200 $\mathrm{ng} / \mathrm{ml}$. Linear regression analysis indicated that the correlation coefficient $\left(r^{2}\right)$ was greater than 0.999 , and the regression equation was $Y=0.129$ $X+0.001$ with $Y$ as the peak area ratio and $X$ as the concentration of melatonin.

The measured serum melatonin concentrations were found to be in good agreement with the actual concentrations of melatonin prepared by spiking melatonin in human blank sera. The accuracy bias shown in Table 4 ranged from -0.80 to $-5.9 \%$ at the four concentrations evaluated.

Table 3

Intra- and inter-assay precision of serum melatonin

\begin{tabular}{lll}
\hline $\begin{array}{l}\text { Melatonin } \\
(\mathrm{ng} / \mathrm{ml})\end{array}$ & $\begin{array}{l}\text { Intra-assay } \\
(\% \mathrm{CV}, n=5)\end{array}$ & $\begin{array}{l}\text { Inter-assay } \\
(\% \mathrm{CV}, n=3)\end{array}$ \\
\hline 1.00 & 2.0 & 5.9 \\
5.00 & 0.80 & 1.8 \\
25.0 & 1.8 & 1.5 \\
150 & 1.7 & 2.5 \\
\hline
\end{tabular}


Table 4

Accuracy of the serum melatonin measurement

\begin{tabular}{lccc}
\hline Melatonin added $(\mathrm{ng} / \mathrm{ml})$ & Melatonin measured $(\mathrm{ng} / \mathrm{ml})$ & Accuracy bias $(\%)^{\mathrm{a}}$ & $\% \mathrm{CV}(n=5)$ \\
\hline 1.00 & 0.941 & -5.9 & 2.0 \\
5.00 & 4.95 & -1.0 & 0.80 \\
25.0 & 24.8 & -0.80 & 1.8 \\
150 & 146 & -2.7 & 1.7 \\
\hline
\end{tabular}

${ }^{\text {a }}$ Accuracy bias $(\%)=($ measured value - nominal value $) /$ nominal value $\times 100$.

The limit of detection defined as the signal-tonoise ratio of 3 was $0.100 \mathrm{ng} / \mathrm{ml}$ for serum melatonin $(n=3)$ and the limit of quantitation defined as the lowest detectable analyte concentration which has an accuracy bias of $18 \%$ was 0.500 $\mathrm{ng} / \mathrm{ml}$ for serum melatonin $(n=3)$.

In comparison with the previously reported atomspheric pressure chemical ionization (APCI)MS-MS method [20], it is clearly evident that our ESI-MS-MS method for serum melatonin has lower limit of detection and wider linear dynamic range, are capable of handling larger amount of sample and higher flow rates.

\section{Applicability to pharmacokinetic studies}

According to Dollins et al. [9], melatonin doses at $1 \mathrm{mg}$ or greater were needed to generate peak serum melatonin levels that exceeded the normal range of nocturnal melatonin levels in untreated people, which corresponded to peak serum melatonin levels $0.500 \mathrm{ng} / \mathrm{ml}$ or higher.

The method developed has a limit of quantitation of $0.500 \mathrm{ng} / \mathrm{ml}$ with $10-\mu 1$ sample injection, which is suitable for the pharmacokinetic study of melatonin at doses greater than $1 \mathrm{mg}$. It should also be pointed out that the extraction cartridge used in this work has concentration capability, which allows us to injection sample volumes up to $50 \mu \mathrm{l}$ without sacrificing the analyte recoveries. Therefore, if lower limits of quantitation are desirable, larger sample volumes can be used. Although the method developed has not yet been tested with clinical samples, its applicability to serum melatonin has been demonstrated.

\section{Conclusions}

A rapid, simple and sensitive analytical method for the quantitative determination of melatonin in human serum has been developed and validated. It employs on-line sample preparation and ESIMS-MS detection. Serum samples can be directly injected into the system and be analyzed within 9 min. The method has wide linear dynamic range, low limit of quantitation, high specificity and sensitivity, as well as excellent reproducibility and accuracy. It may be used for the pharmacokinetic study of melatonin in human sera.

\section{References}

[1] A.J. Lewy, R.L. Sack, Prog. Brain Res. 111 (1996) 205216.

[2] F. Waldhauser, M. Dietzel, Ann. NY Acad. Sci. 453 (1985) 205-214.

[3] K. Petrie, A.G. Dawson, L. Thompson, R. Brook, Biol. Psychiatry 33 (1993) 526-530.

[4] R. Khan, S. Morley, S. Daya, B. Potgieter, in: G. Lubec, G.A. Rosenthal (Eds.), Amino Acids: Chemistry, Biology, and Medicine, ESCOM, Leiden, The Netherlands, 1990, pp. $962-969$.

[5] M.A. Pahlavani, Drugs Today 33 (1997) 25-39.

[6] R.J. Reiter, D.X. Tan, J. Cabrera, D. D'Arpa, R.M. Rosa, J.C. Mayo, S. Ramos, Biol. Signals Recept. 8 (1999) 56-63.

[7] D.E. Blask, L.A. Sauer, R.T. Dauchy, E.W. Holowachuk, M.S. Ruhoff, Adv. Exp. Med. Biol. 460 (1999) 337-343.

[8] M.A. Kane, A. Johnson, A.E. Nash, D. Boose, G. Mathai, C. Balmer, J.J. Yohn, W.A. Robinson, Melanoma Res. 4 (1994) 59-65.

[9] A.B. Dollins, I.V. Zhdanova, R.J. Wurtman, H.J. Lynch, M.H. Deng, Proc. Natl. Acad. Sci. USA 91 (1994) 18241828. 
[10] E. Bechgaard, M. Bagger, R. Larsen, H.W. Nielsen, J. Chromatogr. B 693 (1997) 237-240.

[11] P.G. Rebollar, E. Ubilla, J.B. Peleteiro, M.T. Agapito, J.M.R. Alvarino, J. Physiol. Biochem. 55 (1999) 341-348.

[12] M. Plebani, M. Masiero, A.P. Burlina, M.L. Chiozza, M. Scanarini, A. Burlina, Child's Nerv. Syst. 6 (1990) 220 221.

[13] A. Covaci, C. Doneanu, H.Y. Aboul-Enein, P. Schepens, Biomed. Chromatogr. 13 (1999) 431-436.

[14] J.B. Fourtillan, P. Gobin, B. Faye, J. Girault, Biol. Mass Spectrom. 23 (1994) 499-509.

[15] J.S. Torano, P. Rijn-Bikker, P. Merkus, H.J. Guchelaar, Biomed. Chromatogr. 14 (2000) 306-310.
[16] E. Bechgaad, K. Lindhardt, L. Martinsen, J. Chromatogr. B 712 (1998) 177-181.

[17] E. Chanut, J. Nyugen-legros, C. Versaux-Botteri, J.H. Trouvin, J.M. Launay, J. Chromatogr. B 709 (1998) $11-18$.

[18] http://www.waters.com/Waters_Website/Chemistry/ Oasis/appnotes/intro.html.

[19] F.M. Lagerwerf, W.D. Van Dongen, R.J.J.M. Steenvoorden, M. Honing, J.H.G. Jonkman, Trends Anal. Chem. 19 (2000) 418-427.

[20] F. Xie, P. Wong, K. Yoshioka, R.G. Cooks, P.T. Kissinger, J. Liq. Chromatogr. Rel. Technol. 21 (1998) $1273-1282$. 